\title{
Diablotexto
}

Literatura transnacional en Cataluña:

La filla estrangera de Najat El Hachmi

Transnational literature in Catalonia: La filla estrangera by Najat El Hachmi

\author{
KATIUSCIA DARICI \\ UNIVERSITÀ DI VERONA - UNIVERSITAT POMPEU FABRA
}

Resumen: Mi propuesta se centra en el caso de Najat El Hachmi, sobre todo en relación a su identidad étnico-cultural y a la de la protagonista de la novela La filla estrangera (2015) la hija a la que el título se refiere. Se comenzará dando una definición de Literatura transnacional, describiendo el compromiso con la identidad y la lengua catalana por parte de la escritora, al tiempo que se aborda el tema de la translingüedad. Seguidamente se presentan los puntos claves de la novela, relacionados con el deseo y la búsqueda de una integración cultural difícil pero deseada.

Palabras clave: literatura migrante, literatura catalana, transnacionalismo.

Abstract: My proposal focuses on Najat El Hachmi case study, in particular with relation to the writer's ethnic-cultural identity and the one of the protagonist of the novel La filla estrangera (2015), the daughter the title refers to. First I define de idea of transnational literature in Catalonia, then I describe El Hachmi's compromise with identity and the Catalan language in the light of the phenomenon of translingualism. Second, I present the novel's salient points related to the desire and the seek of a difficult cultural integration.

Key words: migration literature, catalan literature, transnationalism. 
Marroquí de nacimiento y catalana de adopción, Najat el Hachmi publica La filla estrangera en septiembre de 2015 en Edicions $62^{1}$. Es su última novela hasta la fecha y la obra en la que se condensan motivos y tensiones presentes en las anteriores, no solo por lo que atañe a la trayectoria de emancipación individual llevada a cabo por parte de la protagonista, sino, además, por el tema de la identidad que, aun en el marco ficcional, se entrecruza fuertemente con vivencias autobiográficas.

La novela narra la historia de una chica adolescente que vive con su madre en Vic. Las dos se han trasladado a Cataluña por motivos de reagrupación familiar que, desafortunadamente, no llega a tener lugar porque, al llegar las dos mujeres allí, el padre y marido ya se ha juntado con otra mujer. La condición de migrante se desarrolla a través de un monólogo interior de la chica que va contando su experiencia, sobre todo las contradicciones debidas a las dos culturas que conviven en ella y entre las que tiene que dividirse. Por un lado, recibe los estímulos del mundo catalán, la escuela, las lecturas, las amigas y el posible futuro de mujer libre de tomar decisiones. Por otro lado, la herencia de un mundo tradicional, cuyos valores están vehiculados por la madre, la empujan hacia un estilo de vida destinado a una vocación de mujer casada y futura madre. El conflicto entre las dos posiciones, que pasa a través de una crisis personal que roza la neurosis, primero la lleva a cumplir con las expectativas de la madre; luego, con fuerza y valentía no sin consecuencias, la conduce a emprender la trayectoria de la emancipación personal, gracias a unas estrategias de cambio personal hacia una pluralidad cultural apta para facilitar la integración en el tejido social y cultural catalán.

El título de la novela se propone como una intertextualidad con La germana, l'estrangera, poemario de Maria Mercè Marçal que trata de la experiencia amorosa y de lo materno, del cuerpo y de la sexualidad, temas que son también propios de El Hachmi (Chaffee, 2016: s/p). La emancipación personal de la joven protagonista de LFE, así como su búsqueda de integración,

\footnotetext{
${ }^{1}$ Las citas en el original en catalán se toman de la primera edición de septiembre de 2015. En adelante se citará $L a$ filla estrangera como $L F E$. La traducción castellana de referencia es la de la editorial Destino, de Rosa Maria Prats, también publicada en 2015.
} 
pasan necesariamente por la lengua como confín que marca el hecho de ser extranjera en sentido amplio, pues lo es tanto hacia los catalanes como hacia su madre, al no adherirse enteramente a ninguno de los dos universos culturales.

\section{Literatura transnacional en Cataluña}

En el caso que nos ocupa, el transnacionalismo nos sirve de lente para observar el fenómeno que interesa a los escritores que escriben en una segunda lengua tras emigrar al extranjero. Desde esta perspectiva, es posible considerar a Najat El Hachmi una escritora transnacional ya a partir de su primer libro, Jo també sóc catalana (2004) (Rueda, 2010: 103), en el que, al contar sus circunstancias personales, introduce temas que la enmarcan en el fenómeno migratorio. Este enfoque transnacional constituye una perspectiva de análisis más amplia sobre las migraciones actuales con respecto al concepto de literatura migrante: en los últimos años, la idea de frontera ha sufrido un cambio y se vuelto más porosa por "la imposibilidad de mantener [su] [...] integridad [...] ante la presión migratoria" (Velasco, 2009: 32).

Por transnacionalismo se entiende normalmente "un proceso social donde los migrantes operan en campos sociales que traspasan fronteras geográficas, políticas y culturales" (Glick Schiller et al., 1992). Los transmigrantes son migrantes que mantienen vivas las relaciones entre el país de origen y el de llegada (Ambrosini, 2008: 45). Tradicionalmente, se trataba de relaciones de tipo social o económicas. Aunque no todos los migrantes sean transnacionales en sentido estricto, hay que tener en cuenta que ya no es posible considerar las migraciones contemporáneas exclusivamente desde una perspectiva inmóvil y mononacional desde el país de acogida. Esta práctica estaba considerada aceptable hasta los años 70 (Salih, 2008: 92) ${ }^{2}$. Actualmente, los avances en los

\footnotetext{
2 Dos olas migratorias considerables desde la España del sur tuvieron lugar en los años veinte y, más tarde, entre 1950 y los años setenta. Sobre las condiciones de vida de los inmigrantes procedentes de otras regiones de España a Cataluña queda un testimonio importante en Els altres catalans [Los otros catalanes] (1964), de Francesc Candel (1925-2007), cuyo prólogo, publicado por Edicions 62 en 2008, es de Najat El Hachmi. Tras publicar otros volúmenes sobre el tema, (Encara més sobre els altres catalans, de 1966; Els altres catalans vint anys després, de 1985), Francesc Candel publica, en colaboración con Josep Maria Cuenca, Els altres catalans del segle XXI (2001), retrato de los inmigrados del nuevo milenio, procedentes sobre todo del Maghreb, que se interroga en temas de derechos, identidad y política (Valiente y Rambla, 2009).
} 
medios de transporte y de comunicación posibilitan al migrante no solo viajar con más facilidad sino también de mantener lazos con el país de origen (a través de las redes sociales, el uso de los servicios de envío de dinero, etc.) para que el traslado suponga un choque afectivo y cultural más leve (Velasco, 2009: 35).

En Cataluña la inmigración ha sido una "constante histórica" (Besalú, 2009: 281), indicativa del grado de prosperidad económica del país: un índice alto de inmigración es señal de bienestar económico y demográfico ya a partir del siglo XIX ${ }^{3}$. En la actualidad, respecto al pasado, la novedad consiste en el hecho de que los que vienen de fuera proceden casi enteramente del extranjero (282). Como comunidad autónoma que en las últimas décadas ha registrado un número muy consistente de inmigrados extranjeros, sobre todo de Marruecos (Castellano, 2011), Cataluña se ha convertido en un crisol de culturas. En este contexto ha surgido una literatura de autores nacidos en el extranjero que escriben en castellano o catalán. Son escritores que "emprenden una nueva línea de lecturas que apuestan por una educación intercultural real, abriendo las puertas [...] al diálogo entre culturas y al ejercicio activo de la ciudadanía" (ibíd.). Entre las voces literarias presentes en el panorama de la actualidad catalana, cabe mencionar a Asha Miró, Najat El Hachmi, Agnès Agboton, Salah Jamal, Pius Alibek y Simona Šcrabec (ibíd.). Son figuras que se adhieren a una opción lingüística translingüe por el hecho de escribir en catalán, y mantienen una subjetividad híbrida, debido a su nacimiento fuera de España. En su escritura esto se traduce en un espacio de reflexión y diálogo entre diferentes culturas gracias a su "perspectiva periférica y transnacional" (ibíd.). La negociación entre pasado y presente, entre el aquí y el allá, está en evolución continua. Aquí nos parece importante puntualizar que, al hablar de "adhesión a una opción lingüística translingüe" nos referimos a la elección de escribir en L2, recurriendo a la definición de Aitana Guia acerca de la "condición de [los] inmigrantes de segunda Generación" o la de los que han elegido referirse a un público europeo y se han identificado con la lengua del país de acogida (2010: 31). Existe, sin

\footnotetext{
${ }^{3}$ Cabe señalar el cambio de tendencia que irrumpió con la crisis de 2008, cuando la ola migratoria que había iniciado en los años ochenta, conoció una suspensión repentina (Arnau i Segarra, 2016, nota 1).
} 
embargo, una formulación específica para una categoría definida "literatura translingüe", la cual se refiere a "obras bilingües o multilingües que no contienen traducciones. En la literatura translingüística no hay glosarios, ni traducciones adjuntas, ni tampoco notas con traducciones" (Gernalzick, 2013: 81). En estas obras ninguna de las lenguas presentes está considerada como primaria, así que no hay relaciones de subordinación entre lenguas (ibíd.). Las obras translingües son relativamente escasas debido a una noción de monolingüismo ideológico y a las teorías de las naciones herederas de la época romántica (ibíd:: 82). Borderlands/La frontera: The New Mestiza, postmodernist prose and poetry (1987), de Gloria Anzaldúa, es considerado un libro (casi) del todo translingüe (ibíd:: 89-90). Si bien LFE no posee plenamente este rasgo translingüe, observamos una serie de palabras y expresiones en tamazight por las que no se presenta su correspondencia traducida en catalán. Más que una obra translingüe en sentido estricto, es posible adscribir LFE a un marco transcultural de obras que presentan problemáticas lingüísticas con presencia detallada de palabras procedentes del diccionario de más de una lengua y donde ninguna de las lenguas o culturas se propone como dominante.

El año 2004 marca un antes y un después en la literatura transnacional en Cataluña (Castellano, 2011: s/p). Aunque existe alguna obra anterior, en ese año se publican dos libros particularmente significativos: De Nador a Vic de Laila Karrouch, y Jo també sóc catalana de Najat El Hachmi ${ }^{4}$. Karrouch y El Hachmi son, de hecho, "las primeras escritoras bereberes-catalanas en publicar obras de autoficción y narrativa de gran calidad en catalán" (Pérez-Sánchez, 2014: 13). El dato significativo, según Ana Rueda, está en que se trata de dos mujeres muy comprometidas con el mundo literario y que escriben en catalán, lo que fortalece la "fusión entre el tejido cultural del mundo que habitan, el idioma en que se expresan, y la identidad multicultural que surge de esa confluencia de factores"

\footnotetext{
${ }^{4}$ En el título Jo també sóc catalana observamos una referencia a una frase de efecto que es posible encontrar en Francesc Candel (1964: 52): al visitar una escuela de Sant Ildefons durante el periodo de redacción del libro Els altres catalans, Candel le preguntó a un maestro cuántos niños catalanes había. Cuenta Candel: "El maestro, que entendió mi pregunta [...] contestó: "Dos, quizás tres, como mucho». Sin embargo, ya más de la mitad de los niños, que habían oído la pregunta, habían alzado la mano, exclamando: "Señor maestro, yo también soy catalán»." [Subrayado y castellano en el original].
} 
(2010: 103). Con palabras de Sara Bernechea, es posible afirmar que El Hachmi y Karrouch "participan en el circuito nacional como así lo demuestra la edición de sus obras, la participación en premios literarios" y en acontecimientos públicos (2013: 27). Ambas escritoras comparten los temas propios de las novelas sobre experiencias migratorias: los datos biográficos, la importancia de la oralidad en las sociedades de origen, el hecho de ser mujer en un país occidental, la búsqueda de una emancipación y, finalmente, la elección de una lengua adecuada a la narración (Castellano, 2011). Sus libros pueden considerarse una forma de "discurso testimonial" (Arnau i Segarra, 2016: s/p) que reivindica un nuevo género: las protagonistas emprenden un ciclo de aprendizaje asimilable a las características propias del Bildungsroman (Ricci, 2010c: 51) donde la escritura representa un lugar de reflexión y reivindicación de libertad personal, de mayor peso económico y social en el país de acogida sin dejar de confrontarse constantemente con los valores patriarcales impuestos por la familia de origen (Arnau i Segarra, 2016: s/p).

\section{La identidad fronteriza en primera persona: Jo també sóc catalana}

Najat El Hachmi nació en 1979 en Nador, en el norte de Marruecos. A la edad de ocho años se trasladó a Vic, en Cataluña, por motivos de reagrupación familiar tras la emigración de su padre algunos años antes ${ }^{5}$. La inmersión en la nueva realidad de una capital de comarca caracterizada por una preferencia del uso del catalán frente al castellano, además de la escolarización en la misma lengua ${ }^{6}$, proporcionaron la rápida incorporación de la joven Najat a la cultura de acogida. Su curiosidad natural por conocer el nuevo país y el interés por la lectura de obras literarias en catalán la ayudaron al proceso de acercamiento al

\footnotetext{
${ }^{5}$ Algunos proponen referirse a los niños que llegan al país de migración como "generación 1,5" (Rubén Rumbaut apud Pérez-Firmat,1994; s/p; Bernechea, 2013: 27), es decir, la generación que es "fruto de la reagrupación familiar" (Arnau i Segarra, 2016, s/p). Las obras de los escritores de la generación 1,5 en Cataluña, de la que El Hachmi forma parte, también pueden enmarcarse en las que se pueden Ilamar "escrituras del yo híbrido" (ibíd.). El Hachmi ha declarado preferir, entre todas, la denominación "generación de frontera" (JTSC: 13).

${ }^{6}$ La lengua vehicular del sistema escolar en Cataluña, desde la primaria a la universidad, es el catalán. Sobre la situación actual de la lengua catalana junto a una breve referencia histórica, $c f$. Marí Mayans (2015).
} 
entorno. Najat El Hachmi se define como "una lectora voraç pràcticament des de que [...] [va] aprendre a llegir en català"7. Ya desde muy joven, pues, es una lectora voraz de novelas en catalán en cuyas historias puede reflejarse. Las obras de referencia son Aloma de Mercè Rodoreda y Solitud de Victor Català, "cuya protagonista es una mujer que cambia de residencia para casarse y describe las adversidades de la vida en la montaña, una dureza parecida a la de la campaña donde yo vivía" (Chaffee, 2016).

En su primer libro, Jo també sóc catalana ${ }^{8}$ (2004), El Hachmi relata su experiencia personal en forma de autobiografía novelada ${ }^{9}$. Al tratar el "proceso de adaptación del inmigrante a la sociedad de acogida" (Muñoz Carrobles, 2015: 40) la escritora aborda temas de lengua e identidad fronterizas. Más allá de las vivencias relacionadas con el traslado y la formación en Cataluña, se describen sobre todo las dificultades que supone para las mujeres de religión musulmana vivir en una comunidad inmigrante en Cataluña.

En la recuperación del pasado a través del recuerdo personal, el tú al que la escritora se dirige es a la vez íntimo (su hijo pequeño) y colectivo (los que han vivido la experiencia migratoria o la están viviendo) ${ }^{10}$. Es íntimo, porque recurre a la relación madre-hijo para que no se pierda del todo el enlace con Marruecos. Este rasgo "permite al lector constatar el impacto de la migración en la línea generacional" (Rueda, 2010: 102). Por otra parte, es colectivo, pues propone despertar la conciencia de la opinión pública sobre el hecho migratorio. Es importante subrayar el papel activo de los lectores en la literatura de la migración: al estar involucrados en la lectura de una de las posibles interpretaciones de su mundo por parte de un autor inmigrante que se propone como intérprete, con una mirada diferente: "Ios lectores, al leer, cuestionan su cultura y la cosmovisión

\footnotetext{
7 "Una lectora voraz desde que aprendió a leer en catalán" (El Hachmi, 2004: 13-14).

${ }^{8}$ En adelante Jo també sóc catalana se citará como JTSC.

${ }^{9}$ No se ha realizado hasta la fecha una traducción castellana de este libro, por ser considerado demasiado "catalanista" (Ricci, 2010b: 90). Sin embargo, algunos fragmentos de los capítulos 1 y 2 están disponibles en traducción castellana (a cargo de Sílvia Roig-Martínez) en Rueda (2010: 245-255).

${ }^{10}$ En JTSC (p. 60), El Hachmi observa a unos niños recién llegados de Marruecos mientras desenvuelve su trabajo como mediadora. Su reflexión sobre el cambio que están a punto de vivir en sus personas lo origina el hecho de verse reflejada en ellos y de saber que pronto empezarán a hablar catalán entre ellos, e incluso la piel les cambiará de color al hacerse más clara; pronto esos niños mirarán atrás y se verán diferentes de lo que eran.
} 
personal" en una actividad crítica participativa (Berlage, 2013: 53). Además, la narración de una experiencia personal con ojo de migrante abre paso a un debate más amplio en las sociedades globalizadas que tiene que ver, entre otros temas, con "el sistema patriarcal, [...] el colonialismo, [...], la xenofobia, el miedo a la diferencia, [...] la política discriminatoria, la burocracia infinita" (Rueda, 2010: 57).

\section{El compromiso con la identidad y la lengua}

Tal como en los años setenta Montserrat Roig fue "una de las voces que explicó el mundo desde unos ojos de mujer" (Real, 2009: 622), Najat El Hachmi, cuyas referencias culturales incluyen a la misma Roig, es una de las voces que explican el mundo desde la mirada de una mujer migrante. Para El Hachmi, la lengua es un confín inscrito en el cuerpo como una línea imaginaria que divide interiormente: la emigración y el proceso de integración, al que acompaña inevitablemente cierto grado de desintegración, son factores constantemente presentes en su trayectoria artística y vital. La migración, considerada como "perdurable situación de tránsito" (Gnisci, 2010: 2), concierne de hecho, y a la vez, a la identidad de la escritora y al tema de la novela LFE. Motivo relevante en la escritura de El Hachmi, la lengua representa el lugar de escisión que la divide metafóricamente en dos mitades. Es una sensación de ruptura que invade a la escritora en su experiencia migrante y que repercute en la novela a través de metáforas relativas a confines que se trazan en el cuerpo de la protagonista.

Se han ensalzado a menudo la "translingüedad" de El Hachmi y su condición de migrante, haciendo de ella un caso literario por esta razón. Sin olvidar el papel que, sin duda, su origen juega en su escritura y en los temas tratados, hay que tener en cuenta que

la opción lingüística transligüe de muchos autores inmigrantes, resaltada por editoriales y medios de comunicación, no es tan significativa como los temas que tratan en su obra literaria. La adopción de lenguas europeas es una opción lógica debido a la trayectoria vital de estos autores (Guia, 2010: 32).

Limitar la consideración de su obra a su historia personal es reductivo. A 
este respecto, Najat El Hachmi habla de "pornografía étnica" con referencia a la tendencia de las sociedades occidentales de relegar al extranjero a una condición migrante perpetua:

Los pornógrafos de la etnicidad acentúan rasgos de ti que en tu país encontrarías ridículos. Se quedan con el folclore. Algunas ONG deberían luchar por la igualdad de todos. De viudas, extranjeros, mujeres, ancianos. El inmigrante no quiere pertenecer a una asociación de inmigrantes, sino a una de vecinos... Sobre los marroquís pesan una serie de estereotipos (Vidal Claramonte, 2012: 241).

De hecho, existe la necesidad, por parte de las sociedades de acogida, de institucionalizar la literatura migrante convirtiendo la experiencia migrante en algo fijo e inmutable. Es lo que se llama "inmigridad", es decir, "la estrategia de convertir al «migrante» en una condición permanente y hacer de la provisionalidad un estatuto fijo" (Akaloo, 2012: 258). En esta visión, el migrante siempre será un "recién llegado, aún en tránsito" (ibíd.). El asunto es aún más contundente cuando El Hachmi describe uno de los diálogos que pueden tener lugar en una situación normal entre autóctonos e inmigrados: "Què és el que més t'agrada d'aquí?"11 (JTSC: 62), es la pregunta que le hacen a Najat El Hachmi en una situación de cotidianidad. Hablando entre sí para explicarlo al lector, su respuesta resulta tajante y esclarecedora de la situación y del estado de ánimo que una postura como esta genera en ella:

Les teves paraules només demostren que no t'he sabut transmetre el meu missatge, o bé no m'has escoltat en tota l'estona. Aquesta pregunta es fa a un turista, a algú que està de pas, que va a veure museus i muntanyes, mitja pensió amb ampolleta de xampú de regal. Et puc contestar que la Sagrada Família o les platges abruptes de la Costa Brava, però prefereixo que reflexionis i et dic: "I a tu què és el que te agrada més d'aquí?" (JTSC: 62$)^{12}$.

Tras más de quince años viviendo en Cataluña, El Hachmi todavía se enfrenta con una mentalidad que sigue considerándola extranjera, marroquí, y

\footnotetext{
11 “¿Qué es lo que más te gusta de aquí?” (JTSC: 62).

12 "Tus palabras sólo demuestran que no he sabido transmitirte mi mensaje, o bien que no me has escuchado todo el tiempo. Esta pregunta se hace a un turista, a alguien que está de paso, que va a ver museos y montes, media pensión con media botellita de champú en regalo. Puedo contestarte que la Sagrada Familia o las playas abruptas de la Costa Brava, pero prefiero que reflexiones y te digo "Y a ti, ¿qué es lo que más te gusta de aquí?»" (JTSC: 62).
} 
lucha diariamente para afirmar que ella es "més d'aquí que de cap més lloc" (JTSC: 62) ${ }^{13}$ y que su amor al país no es distinto del de los que nacieron en Cataluña. Aunque en JTSC explica cómo, al final, "la sociedad los obliga [a los niños] a definirse por una cultura, con el menosprecio de la otra" (Castellano, 2011), El Hachmi insiste en la importancia de una doble pertenencia, sin que esto suponga el menosprecio o la no consideración de la otra (Muñoz Carrobles, 2015: 40). A este propósito, ha de considerarse que, como en el caso de Laila Karrouch, su catalanidad no se define por medio de la antítesis a lo marroquí ni a lo amazigh, sino que se trata de la adquisición de una nueva pertenencia que se añade a las demás, enriqueciéndolas (Ricci, 2010a: 213 y 2017: 586). Es lo que El Hachmi considera tener "un pensamiento de frontera" (JTSC: 14), pertenecer a dos o más identidades a la vez:

Des d'aquell moment van existir dues Najats al món: una, la marroquina, seguia amb els costums anhelats, jugava a fer de núvia amb els mocadors de la mare, somiava en festes de dones ballant la dansa del ventre, de portes endins, i l'altra, la catalana, es mostrava de portes enfora. Cap de les dues parlava de l'altra, el pacte de silenci s'havia establert per no tornar a sentir la vergonya ${ }^{14}$.

Es también lo que he definido como "identidad transcultural", de hecho "hoy imaginamos lo que significa ser sujetos no solo desde la cultura en que nacimos, sino desde una enorme variedad de repertorios simbólicos y modelos de comportamiento" (García Canclini, 2004: 161). Sin embargo, la otra cara de la moneda de la doble pertenencia es el peligro a la desintegración y el no sentirse de "cap lloc"15 (JTSC: 91), como es su caso y el de cuantos han vivido su misma experiencia.

Al mismo tiempo, si las clasificaciones pueden ayudar a entender situaciones, aunque sea a un primer nivel de lectura, también hay que olvidarse de ellas parcialmente. Lo afirma muy claramente El Hachmi en el prólogo de

\footnotetext{
13 "Más de aquí que de ningún otro lugar" (JTSC: 62).

14 "A partir de ese momento existieron dos Najats en el mundo: una, la marroquí, seguía con las costumbres anheladas, jugaba a ser novia con los pañuelos de la madre, soñaba con fiestas de mujeres bailando la danza del vientre, de puertas adentro, y la otra, la catalana, se mostraba puertas afuera. Ninguna de las dos hablaba con la otra, el pacto de silencio se había establecido para no volver a sentir la vergüenza". [Salvo que se indique lo contrario, todas las traducciones de textos citados en la bibliografía en lengua no española son de la autora].

15 "De ningún lugar" (JTSC, 91).
} 
JTSC cuando confiesa tener el sueño de poder dejar de hablar de inmigración, es decir, abandonar las etiquetas que el lugar de nacimiento proporciona:

Tots tenim un somni, un ideal imaginari l'existència del qual és necessària per tal de continuar endavant: el meu és poder deixar de parlar d'immigració algun dia, no haver de donar més voltes a les etiquetes, no haver d'explicar per enèsima vegada d'on vinc o, si més no, que aquest fet no tingui el pes específic que tè. De moment, però, no sembla que la nostra societat tingui prou experiència en aquest camp per poder arribar a aquest estat de maduresa en el tracte de la diversitat, un tracte que no ha de discriminar en negatiu, però que tampoc hauria de ser significatiu, no hauria de distingir els individus pel lloc on van nèixer (JTSC: $12)^{16}$.

La desintegración que acabamos de mencionar está causada, desde luego, por la confrontación con el otro, en el "trato de la diversidad" (JTSC: 12) que, si por un lado pide al extranjero continuar siendo peculiar dentro de un marco de separación y diferencia con lo local, por otro lado, explica El Hachmi, obliga a la pérdida total de los rasgos propios:

Quan algú et diu que t'integris, el que en realitat t'està demanant és que et desintegris, que esborris qualsevol rastre de temps anteriors, de vestigis culturals o religiosos, que ho oblidis tot i només recordis els seus records, el seu passat (JTSC: 90$)^{17}$.

Como se ve, "vivir en tránsito" supone volver a modelar y estructurar continuamente la persona y las relaciones culturales en la que se inserta y esto puede llevar sin duda a una deconstrucción de la subjetividad (García Canclini, 2004: 161).

\section{Escribir en catalán como acto natural}

\footnotetext{
16 "Todos tenemos un sueño, un ideal imaginario cuya existencia es necesaria para seguir adelante: el mío es poder dejar de hablar de inmigración algún día, no tener que dar más vueltas a las etiquetas, no tener que explicar por enésima vez de dónde vengo 0 , al menos, que este hecho no tenga el peso específico que tiene. De momento, sin embargo, no parece que nuestra sociedad tenga suficiente experiencia en este campo para poder alcanzar este grado de madurez en el trato de la diversidad, un trato que no debería distinguir a los individuos por el lugar donde nacieron".

17 "Cuando alguien te dice que te integres, lo que en realidad te está pidiendo es que te desintegres, que borres cualquier rastro de tiempos anteriores, de vestigios culturales 0 religiosos, que lo olvides todo y solo recuerdes sus recuerdos, su pasado" (JTSC: 90).
} 
Mucho se ha hablado de Najat el Hachmi en términos de escritora migrante que escoge escribir en catalán, atribuyéndole a este elemento un matiz tal vez político no presente en las intenciones, por lo menos iniciales, de la escritora. Pero antes de la consideración del sistema de valores en el que El Hachmi decide insertarse, hay que tener en cuenta que Vic se halla en una de las zonas de Cataluña donde la población nativa, a la hora de su llegada, hablaba preferentemente catalán. Este dato resulta significativo, pues la lengua de expresión escrita de un autor es, sobre todo, la lengua en la que él mismo se siente cómodo en expresarse de forma narrativa. El Hachmi ha declarado más de una vez públicamente que, al ser el catalán la lengua de su alfabetización, escribir en esta lengua ha sido desde el principio un acto natural. Por esto, es importante subrayar que el rechazo de El Hachmi a hablar de "elección" (Song, 2014: 49), pues hablar una lengua no es algo sobre lo que se pueda razonar, sino que es un acto normal. De hecho, se podría decir que la reivindicación más importante es simplemente la de hablar la lengua en la que uno mismo se siente a gusto de hablar, teniendo en cuenta que el catalán para El Hachmi es la primera lengua con la que entra en contacto nada más llegar a Cataluña al mismo tiempo que su primera lengua de alfabetización. Esta postura recuerda a la de Montserrat Roig, que El Hachmi considera uno de sus modelos culturales y literarios. En una conversación con Geraldine Nichols, Roig explicaba que, para ella, "escribir en catalán era como respirar. Incluso no era casi ni un hecho político, sino una identificación muy fuerte con el entorno" (1989: 53). El pensamiento de Roig encuentra más definición en Digues que m'estimes encara que sigui mentida, donde afirma: "Si em pregunten per què escric en català, se m'acuden tres raons: primer, perquè és la meva llengua; segon, perquè és una llengua literària; $i$, tercer, escric en català perquè em dóna la gana" (1991: 28) ${ }^{18}$. Este pensamiento se inserta en la dificultad todavía existente para los escritores de escoger su lengua literaria porque se trata de un acto con implicaciones políticas y sociales y que repercute en las expectativas del público y de la crítica

\footnotetext{
18 "Si me preguntan por qué escribo en catalán, se me ocurren tres razones: primero, porque es mi lengua; segundo, porque es una lengua literaria; $y$, tercero, escribo en catalán porque me da la gana".
} 
(Heinemann, 1996: 20).

Para un escritor bilingüe o hasta trilingüe (tamazight, catalán, castellano, como en el caso que aquí nos ocupa) cada lengua es un mundo con sus límites y referencias. Normalmente la elección de una lengua tiene que ver con la conciencia de tener un destinatario específico (Angelini, 2013: 68-69) o "participar en una tradición o sistema literario determinado" (Bernechea, 2013: 27). Es más: escribir en una lengua o en otra significa dar voz a uno de los mundos culturales al que se pertenece (sin que dejen de relacionarse los horizontes culturales que uno mismo reúne en sí). Según Carmine Chiellino, los escritores que decidan escribir en L2 o, por usar su definición, los escritores interculturales, se encuentran en la necesidad de establecer un punto cero creativo de la lengua del país de llegada: "un punto cero se produce cada vez que hombres y mujeres empiezan a escribir en una lengua en la que no tienen pasado alguno y, de ahí, que sean inducidos a entender la lengua elegida como tabula rasa" (ibíd.: 92). Se trata de un "sentimiento de pertenencia a la lengua", desde un punto de vista estético más que por lo que tiene que ver con la lengua de uso cotidiano, y que está facilitado cuando el escritor decide empezar con una obra autobiográfica (ibíd:: 97). Es lo que podemos pensar que le pasa a El Hachmi con su comienzo, Jo també sóc catalana. El siguiente paso es hacer una especie de comparación-incorporación de las "diferencias éticas y estéticas" entre las dos lenguas (ibíd.) y esto es algo que nos parece reconocer en la búsqueda constante de correspondencias entre términos y expresiones de una y otra lengua para medir las equivalencias entre las dos pero, quizás también, para medirse a sí misma en su capacidad expresiva a nivel profundo como hasta lograr la capacidad máxima de expresión de algo tanto íntimo que no tiene palabra en tamazight porque es una lengua que carece de vocablos según qué ámbito ( $y$ en la que ella misma carece de conocimiento o su protagonista) y quizás tampoco la tiene en catalán, por pertenecer a un mundo totalmente distinto del de sus orígenes.

La lengua materna de El Hachmi es, para la escritora, una lengua oral, cuyo diccionario carece de expresiones que ella considera intraducibles o que difícilmente lo serían. Sin embargo, la elección de usar el catalán por parte de El 
Hachmi no consiste tanto en el dominio de la lengua sino, sobre todo, en una militancia cultural que infiere, entre otras cosas, la defensa de una lengua -el tamazight, en paralelo al catalán- que El Hachmi percibe como marginada "por ciertos poderes" (JTSC: 52$)$ :

Faig militància per la llengua des que vaig descobrir que ja no hi havia marxa enrere, que ja formava part del meu jo intern sense possibilitat de refer les meves passes. No va ser decisió pròpia venir a parar a Vic, tampoc no ho va ser aprendre la llengua de la seva gent i fer-me-la meva fins al punt de ser-me més fàcil parlar amb el meu fill en català que en amazic. I sent totes dues llengües marginades per certs poders, encara sentia més el deure de defensar-les, d'elevar-les al lloc que els pertoca encara que fos només fent-ne ús (JTSC: 52$)^{19}$.

El tamazight parece encontrarse ahora en una fase de "recuperación, reivindicación y normativización" que recuerda a la del catalán de la Renaixença (Sotorra, 2006: 17) ${ }^{20}$. El Hachmi reconoce un paralelismo entre la historia de las dos lenguas: sea por el régimen de diglosia en que ambas se encuentran o se han encontrado (el tamazight con respecto al árabe, el catalán con relación al castellano), sea porque las dos lenguas ambicionan a adquirir más importancia y autonomía con respecto al gobierno central (Campoy-Cubillo, 2013: 145). No han faltado críticas negativas hacia lo que fue definido como "visión reductiva y nacionalista de la lengua catalana" (Crameri, 2014: 283) y una inclusión en su primera novela (L'últim patriarca) ${ }^{21}$ de posiciones políticas de Convergència i Unió. Además, se ha juzgado como exagerada su postura frente a una hipotética marginalización actual de la lengua catalana ${ }^{22}$. Según Crameri no hay en LUP una explícita referencia al nacionalismo catalán (2014: 283) ni, nos parece, es posible encontrarla en LFE. El interés de El Hachmi tiene que ver con el problema de la lengua, según ella misma afirma (ibíd.).

Al ser uno de los principales países de inmigración de los magrebíes,

\footnotetext{
19 "Hago militancia por la lengua desde que descubrí que ya no había marcha atrás, que ya formaba parte de mi yo interior sin posibilidad de volver sobre mis pasos. No fue decisión mía la de venir a parar a Vic, tampoco no lo fue la de aprender la lengua de su gente y hacerla mía hasta el punto que se me hace más fácil hablar con mi hijo en catalán que en tamazight. Y al ser las dos lenguas marginadas por ciertos poderes, aún más sentía el deber de defenderlas, de elevarlas al lugar que les corresponde, aunque sea solo a través de su uso."

20 En Marruecos existe desde hace algunos años el IRCAM (Institut Royal de la Culture Amazighe) con el fin de valorizar la lengua y la cultura tamazigh (Ricci, 2014: 220).

${ }^{21}$ En adelante se citará L'últim patriarca como LUP.

22 Véase Celaya-Carrillo (2011: 347-348 y 352).
} 
Cataluña representa el país donde se registran los esfuerzos más consistentes en la integración lingüística de los inmigrantes (Campoy-Cubillo, 2013: 142). Hay que observar que las políticas de gestión de la diversidad cultural de las comunidades inmigrantes se insertan en Cataluña en un debate preexistente entre la lengua hegemónica (el castellano) y la periférica (el catalán) para el mantenimiento de la segunda. Desde que el catalán ha adquirido estatuto de lengua oficial en Cataluña, es decir, a partir de la Transición democrática de 1978 en España, mucho se ha hecho en dirección del bilingüismo. Aun así, la línea entre diglosia y bilingüismo es muy sutil y unas variaciones demográficas considerables pueden causar en cualquier momento alteraciones del equilibrio conseguido hasta revertir Cataluña a una situación de diglosia (ibíd:: 145). Tal vez por eso son muchas las iniciativas hacia el apoyo y el fomento de la visibilidad del tamazight en Cataluña, para que, a través de la defensa del tamazight como lengua minoritaria se fomente una relación de ayuda mutua entre el tamazight y el catalán (ibíd.). Quizás la más importante, en 2007, fue la creación del Observatori Linguamón de la Llengua Amaziga en cooperación con la Universidad Autónoma de Barcelona y la Universidad de Cádiz (ibíd., 144). E objetivo del Observatorio es el de defender las lenguas minoritarias con respecto a las hegemónicas (ibíd:: 146). En un esfuerzo común de defensa de lo que en distintos momentos fue definido como llengua pròpia (autóctona) o llengua històrica de Cataluña, en paralelo al reconocimiento de la importancia de apoyar las reivindicaciones en materia de política lingüística del tamazight, el Observatorio impulsa la integración de los marroquíes sin exigirles dejar su lengua de origen, consiguiendo el objetivo de defender el tamazight y el catalán a la vez (ibíd.).

Volviendo a El Hachmi hay que tener en cuenta, además, el hecho de que las referencias literarias de la escritora son prioritariamente catalanas (Mercè Rodoreda, Montserrat Roig, Víctor Català) (JTSC: 79) y no castellanas. Sin embargo, resulta necesario insistir sobre el uso del término "elección" que no parece totalmente correcto, ya que presupone una acción consciente, una toma de posición. Como hemos afirmado anteriormente, se trata de una idea que El Hachmi rechaza, como se puede leer en una entrevista concedida poco después 
de la publicación de la traducción castellana de LUP, mucho se ha hablado de la elección de la lengua como problema literario en el ámbito catalán, pues en Cataluña la realidad cotidiana se caracteriza por una alternancia de castellano y catalán y "la coexistencia de [...] dos lenguas y culturas es más intensa que en otras comunidades bilingües, y está presente en la vida pública como tema de debate y como problemática" (Heinemann, 1996: 1-2). Como figura que históricamente se toma en consideración como personalidad de relieve particularmente involucrada en el tema, Montserrat Roig se dio cuenta en su momento de que "el escritor catalán ha tenido, y tiene, un grave problema de identidad" (Jordi Carbonell apud King, 2005: 1). Un gran número de escritores catalanohablantes, por ejemplo, escriben en castellano ${ }^{23}$. Mientras que es reducido el número de autores que escriben en las dos lenguas, se dan casos de etapas en la que un mismo autor se ha expresado en una lengua y luego en la otra (Heinemann, 1996: 2-3)24. Las razones del fenómeno relacionado al hecho de escribir en una u otra lengua a menudo tienen que ver con la lengua de la enseñanza en la escuela que, durante los años de la dictadura, era el castellano. No solo el catalán estaba desprestigiado durante ese periodo, sino que, además, el gobierno central ambicionaba a una "uniformidad cultural basada en la lengua castellana" (King, 2005: 1). Existe, pues, "toda una generación prácticamente analfabeta en la propia lengua, circunstancia que afectó tanto a los escritores como al público" (Heinemann, 1996: 20). Ya a partir de finales de los años noventa la situación de la lengua catalana ha alcanzado cierta normalidad, pero sería un error expresarse en términos de elección lingüística en sentido estricto (ibíd.). De hecho:

El escritor raramente se formula la pregunta de qué lengua ha de escoger. En una sociedad unilingüe la cuestión no tiene sentido: escribe necesariamente en su lengua, al nivel que sea. [...] En una situación de bilingüismo ambiental el comportamiento del escritor es generalmente el mismo: es decir, no hay

\footnotetext{
${ }^{23}$ Entre los más conocidos: Carlos Barral, Jaime Gil de Biedma, Ana María Matute, los hermanos Goytisolo, Manuel Vázquez Montalbán, Eduardo Mendoza, Juan Marsé, Esther Tusquets, Cristina Fernández Cubas.

${ }^{24}$ Por ejemplo, Terenci Moix escribe en catalán hasta los comienzos de los años ochenta y luego se expresa en castellano contrariamente a lo que pasa en el caso de Pere Gimferrer, quien empieza su carrera en castellano y pasa luego al uso exclusivo del catalán (Heinemann, 1996: 2-3).
} 
"elección", porque el escritor está condicionado por la lengua que usa habitualmente. En efecto, en Cataluña encontraríamos muchos casos en los que la elección, en un sentido estricto, no se ha producido. (Francesc Vallverdú, 1969 apud Heinemann, 1996: 20-21).

Para El Hachmi la lengua representa un sistema de símbolos por medio del cual tener "acceso a la cultura compartida y a sus significados, construyendo así su identidad cultural" (Mancini, 2006: 30). La identidad cultural de la escritora está caracterizada por la presencia de dos códigos culturales, el marroquí y el catalán: la condición de división, partición y pensamiento fronterizo se transfiere en la novela $L F E$ como condición connatural a la protagonista, quien se hace portadora de la palabra nueva (la nueva identidad que mira hacia el futuro), como de la vieja (la identidad de origen, enraizada en el pasado).

\section{La traslación lingüística. La lengua madre}

En LFE se encuentra una reflexión muy importante en torno a la lengua como lugar en el que establecer puntos de encuentro y de mutua comprensión entre culturas. En un estudio sobre LUP, Vidal precisa que "el lenguaje es el medio a través del cual las culturas tienen que llegar a entenderse" (2015: s/p). Símilmente Cristián $\mathrm{H}$. Ricci añade que "el entrecruzamiento y la amalgama de lenguas ha sido esencial en el forjamiento" (2010b: 81) de la personalidad de El Hachmi como escritora, con una mirada crítica hacia la realidad social de los mundos culturales a los que pertenece (ibíd.).

En LFE la referencia a la lengua tamazight y a la catalana se hacen como algo ajeno de sí, como si las dos lenguas no les pertenecieran: siempre reflexiona en términos de "seva llengua" ("su lengua", según hable de la lengua de origen o la catalana) y nunca de "meva llengua" ("mi lengua”). Por lo que atañe al tamazight, la chica lo considera la lengua de la madre. Se habla del tamazight como de un idioma oral que ya nadie sabe escribir y cuyos últimos rastros son un dibujo más que un alfabeto (LFE: 106-107) pues "fa segles que només s'escriu en les seves [de las mujeres] pells"25 (LFE: 24). También es una lengua

\footnotetext{
25 "Hace siglos que solo se escribe sobre su piel” (El Hachmi, 2015b: 28).
} 
que la hija intenta "rescatar de la memòria"26 (LFE: 31) y por la que emprende una actividad continua de traducción. Es así como intenta encontrar correspondencias entre las dos lenguas y se da cuenta de que no solo hay contenidos que resultan intraducibles, sino que en algunos casos ella misma es incapaz de recurrir a la "lengua de su madre", tal como la define en la mayoría de los casos en que se refiere al tamazight ${ }^{27}$.

Tot això non sabria ni com dir-l'hi en la seva llengua, no tinc la capacitat expressiva que tenen les dones del nostre poble d'origen, no sé transmetre meravella o admiració ni neguit ni dubte. No em caldrà buscar les paraules. [...] m'aturo els pensaments perquè no sóc capaç de fer la traducció adecuada ( $L F E$ : $102)^{28}$.

El ámbito en el que más dificultad de expresión tiene pertenece al dominio del placer y del deleite, sobre todo físico, algo que en su monólogo interior no censura:

Plaer? Ni tan sols sé dir aquesta paraula en la llengua de la meva mare. Ni tan sols sé si existeix en la llengua de la mare. Ni plaer, ni delit, ni èxtasi, ni res. Encara menys orgasme. Com li puc fer entendre que sento gust en tantes coses estranyes i poc usuals? En coses petites que passen del tot desapercebudes a la resta de la gent, que em fa por que un dia em desbordi del tot, que surti de mi mateixa, però no de ràbia sinò de plaer pur. Així sóc, és el que sóc. Em noto tot de sobte òrfena de paraules, expulsada de la llengua (LFE: 36-37) ${ }^{29}$.

Este desahucio de la lengua recuerda el estatus de orfandad de los deslenguados del que habla Gloria Anzaldúa (1987: 80). Aunque el caso sea distinto, es decir, en el caso de los chicanos tenga que ver con una lengua deslegitimada por ser definida poor Spanish, el caso de los chicanos ofrece

\footnotetext{
26 "Rescatar de la memoria" (ibíd:: 36).

27 "La llengua de la meva mare" (LFE: 22; 93; 106; 159; 170; 171; 174; 194); "la llengua de la mare" (LFE: 22; 36-37; 88; 93; 97; 106; 133).

28 "Ni siquiera sabría cómo explicarle todo eso en su lengua, no tengo la capacidad expresiva que tienen las mujeres de nuestro pueblo de origen, no sé transmitir maravilla o admiración, ni desazón o duda. No me hará falta buscar las palabras. [...] detengo mis pensamientos porque no sería capaz de dar con la traducción adecuada" (El Hachmi, 2015b: 115).

29 "¿Placer? Ni siquiera sé decir esa palabra en la lengua de mi madre. Ni placer, ni deleite, ni éxtasis, ni nada. Y aún menos orgasmo. ¿Cómo puedo hacer que entienda el placer que siento por esas cosas extrañas y pocos usuales? Por cosas pequeñas, cosas que pasan totalmente desapercibidas para el resto de la gente, que temo que un día me desborden del todo, que me hagan salir de mí misma, pero no de rabia sino de puro placer. Así soy, es lo que soy. Me siento, de repente, huérfana de palabras, expulsada de la lengua" (ibíd:: 41).
} 
paralelismos con lo que se presenta en El Hachmi, pues la hija extranjera está luchando por su identidad lingüística, la doble piel de la identidad étnica (ibíd.: 81). Volviendo a las reflexiones de la chica acerca de la lengua, sentirse huérfana de la lengua equivale a un proceso de pérdida de adherencia lingüística total con la madre y, de ahí, de pérdida de raíces lingüísticas. La búsqueda continua de reciprocidad entre las lenguas es, sobre todo, un intento de capacidad de moverse ágilmente entre las dos orillas representadas por las dos identidades, intento que queda desatendido hasta el alcance de una definición más individualizada de la identidad que la acerca definitivamente al catalán. Algunas veces una expresión catalana puede resultar equívoca en tamazight. Por ejemplo, "Avui és el teu dia"30, dicho en el día de la madre, en catalán sirve para felicitar mientras que en la lengua rifeña quiere decir que uno se tiene que morir. Otras veces es necesario crear una expresión ex novo, como en el caso de "partidora de feines" (LFE: 123) ${ }^{31}$, cuyo significado de "mujer fácil" se infiere pero nunca se traduce literalmente. También, por lo general, la novela presenta una serie de palabras de las que no se da la traducción exacta. Se presentan casos de traducción parcial o imperfecta, otros de traducción por medio de una perífrasis; incluso hay palabras cuyo significado está dejado al dominio de la intuición por parte del lector (como acabamos de ejemplificar con "partidora de feines" que, desde luego, está expresado entre comillas para indicar que no es una expresión de uso común). Finalmente, se dan palabras cuya traducción aparece en otro lugar del libro y que requieren la participación activa del lector para recordar o ir buscando el significado en otra página del libro con respecto a la que está leyendo. Todas las palabras no pertenecientes al dominio catalán están en cursiva.

En LFE, para la protagonista, como para Najat El Hachmi, la lengua representa un medio de autoafirmación y una forma de pensar. Sirve para nombrar las cosas del entorno $\mathrm{y}$, en particular, permite una "perspectiva comparativa" entre culturas (Besemeres y Wierzbicka apud Evangelista, 2013:

\footnotetext{
30 "Hoy es tu día" (ibíd:: 53).

31 "Partidora de tareas" (ibíd:: 138). En catalán la expresión aparece en el texto sin resaltar, mientras que en la traducción castellana aparece entrecomillada.
} 
183) que abre camino a la expresión de contenidos y pensamientos que solo pueden surgir de una comparación, de la toma de conciencia de una diferencia. Es así que se abre paso a una "nueva narración" (Evangelista, 2013: 177), la de "un nuevo yo en L2" (ibíd.) que, en el caso de El Hachmi y también de la hija extranjera, se alimenta de la literatura catalana. Su imaginación es heredera de una tradición muy sólida que apoya sus bases en la obra de Montserrat Roig, Maria Mercè Marçal, Gabriel Ferrater, Mercè Rodoreda, Carme Riera y Victor Catalá, por citar algunos, además de escritores universales como James Joyce y Virginia Woolf. En LFE las intertextualidades resultan importantes por tres motivos: enseñar el proceso de enraizamiento de la hija en la cultura de acogida; el despertar en ella de una conciencia de emancipación gracias a la presencia de protagonistas femeninas en las que identificarse o en las que reconocer vivencias parecidas a las de mujeres conocidas. Finalmente, enlazar la autora a una tradición literaria catalana consolidada. Se trata de un proceso natural del que da cuenta también Gloria Anzaldúa: "los libros salvaron mi cordura, el conocimiento abrió los lugares cerrados en mí y me enseñó primero cómo sobrevivir y luego cómo volar" (1987: s/p). Como observa Cristián Ricci, la literatura en Najat El Hachmi representa un proceso terapéutico que ayuda a "problematizar el proceso de adaptación al que se someten los inmigrantes (especialmente los niños) que proceden de culturas norteafricanas" (2010c: 51).

La búsqueda continua de sentidos y equivalencias entre las dos lenguas tiene también repercusiones, de orden social y personal. Por una parte, representa el conflicto y la ambigüedad de su posición frente al mundo occidental. De hecho,

los autores marroquíes que se expresan en castellano y en catalán, lo hacen a pesar de la ambigüedad hacia la lengua materna y/o a propósito de ello, y encuentran en "la contradicción lingüística" un espejo de otras [...] contradicciones que se presentan en el mundo real. Son contradicciones, en todo caso, que se dan en/entre las culturas que habitan (Ricci, 2014: 19).

Tales contradicciones ponen a los escritores en una posición en la que están llamados a recuperar y dar a conocer la identidad histórica de Marruecos, a la vez que "ostentar el conocimiento del mundo occidental" (ibíd.) llegando a una posición intermedia que es la de las literaturas postcoloniales en general 
(ibíd.). La repercusión personal tiene lugar de manera inconsciente: se trata de la lucha hacia una evolución interior para alcanzar una madurez personal y formarse como individuo completo, distinto de la identidad materna. "La lengua simboliza el desacuerdo [de la hija] con su madre, la dificultad de traducir no sólo habla de la lengua, sino además de la relación con su madre", explica la misma El Hachmi (Chaffee, 2016). La lengua es, de hecho, "el medio y el lugar de constitución del sujeto" (Braidotti, 1994: 14): representa un sistema de valores y símbolos culturales en los que uno "determina el contenido de las distintas expresiones del yo" (Mancini, 2006: 30). En la novela, la chica es bilingüe, pero, como es de suponer, su conocimiento de cada uno de los idiomas difiere por ámbito de uso. El catalán es la lengua de la escolarización, de un nuevo yo que desea y necesita identificarse con el país de residencia. Es una lengua en que siente dominar los pensamientos pues, de hecho, es la lengua en la que piensa (LFE: 36, 92). También representa un espacio de respiro y de libertad, lejos de los condicionamientos de la cultura de origen. Gracias a este espacio de alejamiento, por ejemplo, resulta posible para la chica, al encontrar un nuevo yo en catalán, volver a reunirse con las partes de su fuero interno enraizadas en la cultura tamazigh, o sea, en su pasado. Por otra parte, el tamazight es la lengua que ha aprendido de su madre, una lengua que la ancla al pasado y de la que se declara una "parlant deficient" (LFE: 106) $)^{32}$. Esta lengua proporciona un espacio de reflexión sobre la relación con su madre junto a la consideración de su lugar como persona en la sociedad catalana. La negociación identitaria se asienta en un idiolecto en el que se mezclan el tamazight y el catalán (una "barreja de lenguas", $L F E:$ 22) ${ }^{33}$, que impide la comunicación con los demás, fuera del ámbito familiar, ya que solo alguien que fuera tal como ella podría entenderla. La hija representa, de hecho, la última depositaria de una lengua que nadie, aparte de su madre, puede entender:

si hagués d'explicar en aquesta llengua en la qual penso tot el procés de fer el $\mathrm{pa}$, no ho sabria fer, em fallarien les paraules perquè quan ho faig per mi la

\footnotetext{
32 "Soy una pésima hablante del idioma de mi madre" (ibíd.: 121).

33 "Una mezcla de lenguas" (ibíd.: 26).
} 
descripció se m'omple de paraules de la llengua de la meva mare que ningú més pot entendre (LFE: 22$)^{34}$.

Es así como la lengua y la dificultad de expresión plena resulta ser la causa de una soledad impuesta y de un aislamiento con los demás que tiene el riesgo de radicalizarse (Borgna, 2001: 73): "de vegades és impossible fer-te un diccionari, per la simple raó que el problema de donar nom a les coses és teu i de ningú més" ( $L F E: 90)^{35}$. No tiene amigas, aparte las monjas que encuentra en un seminario donde trabaja como ayudante, mujeres que disfrutan de su compañía y de sus cuentos que se parecen mucho a lo que ellas vivieron en su juventud (LFE: 130-131). La semejanza entre la vida de la chica y la de las monjas representa un detalle más para reflexionar sobre la condición de clausura que la joven vive con respecto al mundo de fuera, en el que viven las chicas de su edad.

Josefina Bueno Alonso aclara cómo la identidad se construye en un tercer espacio, que la estudiosa indica como intersticial, entra lo viejo y lo nuevo:

como en muchas otras novelas, la generación de los hijos de la inmigración se encuentra en esta intersección en la cual no pertenecen a la cultura del país de acogida, pero tampoco se sienten identificados con la cultura de origen o la tradición que suelen representar demasiado a menudo las madres. La identidad individual ha de construirse, por lo tanto, en el intersticio de las dos identidades colectivas: por un lado, la catalana, por otro, la marroquí; dos sentimientos concomitantes de alteridad que más que completarse a menudo aparecen como dos pertinencias incompatibles (2010: $s / p$ ).

En LFE la relación entre cuerpo e identidad es muy estrecha y pasa a través del deseo, en varias acepciones. Se trata de un deseo repartido entre aspiración a la integración, la emancipación y no en último lugar, el deseo sexual. Los tres están estrechamente enlazados, hasta el punto de constituir tres facetas de un solo anhelo, el de vivir su propia vida por parte de la joven. Por lo que tiene que ver con la ambición a la integración, ya hemos visto cómo una de las problemáticas es la de estar sometida a modelos culturales por parte de la

34 "Si tuviera que explicar en esta lengua en la que pienso todo el proceso de hacer el pan, no sabría, me fallaría las palabras, porque, cuando lo hago, la descripción se me llena de palabras de la lengua de mi madre que nadie más puede entender" (ibíd.: 25).

35 "A veces es imposible confeccionarse un diccionario, por la simple razón de que el problema de dar nombre a las cosas es tan solo tuyo" (ibíd: : 101). 
sociedad que la reducen a un "mico de fira" (LFE: 78-79) ${ }^{36}$, o sea, un fenómeno peculiar, algo distinto de lo normal. Sin embargo, lo único que ella ambiciona es ser considerada ni más ni menos que como cualquier otra persona. La reducción a fenómeno, o la imposición de un modelo de adhesión cultural por parte del "otro local" (los que nacieron en Cataluña), pasa por unas expectativas que hay que cumplir o por recibir un trato normalmente reservado a los extranjeros. Esto ocurre cuando, por ejemplo, le felicitan su dominio de la lengua catalana: "Parles tan bé la nostra llengua" (LFE: 79) ${ }^{37}$ y en ocasiones afines, como si fuera algo singular hablar la lengua del país de residencia. De manera similar, en un encuentro oficial sobre migración, que tiene lugar en el Fórum, la reconocen como "la noia que va treure un nou a la Sele" (LFE: 78$)^{38}$ y le otorgan un papel de representante extranjera de la comunidad. Esto enorgullece a los miembros de su propia comunidad ${ }^{39}$, pero al mismo tiempo refuerza un papel de peculiaridad de su rasgo de extranjera. Es un camino que tiene que ver con la emancipación personal antes que nada impuesta desde fuera, que atañe a las expectativas de autorrealización, o, en cualquier caso, a los tópicos relacionados con las mujeres marginadas (LFE: 79).

El alejamiento hacia una lengua propia, distinta de la de la familia, pasa también por una reflexión acerca de los modelos culturales de género, pues en la tradición marroquí las mujeres se quedan analfabetas para dedicarse muy pronto a la casa y a la familia: "elles que no saben llegir ni escriure, felices perquè el seu analfabetisme les feia perfectes pel paper que els havien assignat, incapaces de plantejar-se que en podia ser un altre" (LFE: 39$)^{40}$.

En una dualidad muy fuerte entre el adherirse a modelos culturales de la tradición materna y la emancipación en sentido occidental, igual que sus compañeras, la hija se convence inicialmente de que su única manera de abrirse camino a una vida independiente es seguir las huellas de su madre. Esto pasa

\footnotetext{
36 "Mono de feria" (ibíd.: 88).

37 "¡Hablas tan bien nuestra lengua!" (ibíd.).

38 "Tú eres la chica que sacaste un nueve en la «sele»" (ibíd.).

39 "Tota la ciutat se sent tan orgullosa de tu" (LFE: 80). ("Toda la ciudad se siente muy orgullosa de ti" (El Hachmi, 2015b: 89).

40 "Ellas no saben leer ni escribir, felices porque su analfabetismo les hacía perfectas para el papel que se les había asignado, incapaces de plantearse que este podía ser otro" (ibíd.: 44).
} 
también porque, como hemos visto anteriormente, la hija es incapaz de vivir sin confundir su propia identidad con la de la madre. Por eso llega a dejar de leer, no continúa su instrucción tras el examen de selectividad y se casa con un primo que resulta ser escogido por la madre (LFE: 157). Como es de suponer, esto le provoca una sentido de frustración que llega a ser inaguantable:

Jo no ho sóc [feliç] perquè no sé ser sense llegir, encara, encara m’he d'avesar a deixar enrere les paraules, les boniques, les exactes, les poètiques, les que volen dir moltes coses alhora, les que volen dir el que no diuen, les que han fet servir de fa milers d'anys altres persones, les que ja fa segles deien el mateix que diuen ara. Com més lluny sigui de les paraules més podré assemblar-me a la meva mare $(L F E: 158)^{41}$.

El mundo de las letras, de la literatura, de las lecturas, es un mundo visto como peligroso (LFE: 157,159) porque la aleja de los principios tradicionales de buena musulmana. Aun así, decidirá trabajar como mediadora porque, aunque se trate de una actividad que la volverá a acercar a la palabra, "no serà ni de bon tros amb una feina com aquesta que pugui planificar una fugida de la [...] [seva] vida d'ara" (LFE: 161)

Como indicado anteriormente, la clave para interpretar la relación entre la hija y la lengua está en la interacción con la madre. Se trata sin alguna duda de una relación que presenta unas ciertas peculiaridades. Entre las dos mujeres observamos, por ejemplo, una falta de diálogo significativa. Sus intercambios son, más que discursos, exclamaciones e interjecciones (de asombro, por ejemplo, como en el caso del ua aiau!), (LFE: 101) que la hija va describiendo junto al campo semántico de uso según va escuchando y mirando las costumbres de las mujeres que la rodean, sobre todo en casa, al reunirse con su madre. La pobreza de los intercambios verbales ha de reconducirse a otro tipo de comunicación existente entre las dos mujeres, antes de que la hija deje la casa materna. Se trata de un intercambio emocional que tiene el rasgo de una

\footnotetext{
41 "Yo no [...] soy [feliz] porque aún no sé ser sin leer, aún tengo que acostumbrarme a dejar atrás las palabras, las hermosas, las exactas, las poéticas, las que significan muchas cosas a la vez, las que quieren decir lo que no dicen, las que otras personas vienen utilizando desde hace miles de años, las que ya, hace siglos, decían lo que dicen ahora. Cuanto más me aleje de las palabras, más podré parecerme a mi madre" (ibíd.: 178).

42 "No será con un trabajo como este con el que pueda planificar una huida de [...] [su] vida actual" (ibíd.: 181).
} 
interacción preverbal como la que entretiene una madre con su hijo en las primeras fases de vida del niño.

\section{Conclusiones. Hacia una metodología sin fronteras}

El lenguaje que utilizamos es portador de huellas y vidas previas. Cada palabra que elegimos trae consigo la de otras tantas cargadas igualmente de historias prodigiosas que hay que liberar (Vidal Claramonte, 2005: 15).

Cuanto más se pierda la adherencia con el mundo materno y su idioma, tanto más difícil será expresar contenidos relacionados con las vivencias enlazadas con la vida con la madre, tales que, como visto, hacer el pan ( $L F E: 22$ ). La liberación en este caso toma la forma de una reconciliación con el pasado tras poner orden en él, gracias a un proceso de racionalización de los sentimientos a través de una racionalización de las palabras: una recuperación del pasado que es también recuperación, dentro de sí, de una lengua para preparar terreno a un acto de liberación. De la misma forma en que el mundo presente, de su vida en Cataluña, no se puede explicar por completo en tamazight, la hija entiende que su pasado, y todo lo que lo caracteriza, no puede ser expresado en catalán sin recurrir a palabras intraducibles en la L2. En el momento mismo en el que se vuelve a apoderar de lo que conoce de su pasado y de lo que ha aprendido en tamazight, puede pasar de una posición de sumisión a una de dominio, de sí, de su propia vida, de sus decisiones, rehuyendo un poder materno sobre su persona que ya no tiene sentido en la edad adulta. Como ya ocurrido en LUP y en la experiencia de Najat El Hachmi, el catalán llega a ser la lengua a través de la cual expresar, según necesidad, sea su catalanidad, sea su diferencia e hibridez (Crameri, 2014: 291).

Identidad e hibridez representan hoy día dos conceptos fundamentales para entender la sociedad en la que vivimos. Según propone Arianna Dagnino, la perspectiva transcultural resulta ser la "más apt[a] para tratar las complejidades culturales del siglo XXI" (ibíd.: 2012a). Se trata de un paradigma teórico que promueve una nueva metodología sin fronteras con el fin de superar las dicotomías tradicionales de los estudios comparativos (periferia-centro, colonia-imperio, étnico-mainstream, puro-híbrido) (2012a: 1) Ilegando a una nueva postura, la del "comparatismo transcultural" (ibíd., 2). 


\section{BiBLIOGRAFÍA}

AKALOO, Nasima Nisha (2012). "We are immigrants only in the eyes of others. I am not an immigrant in my own eyes. Representaciones interculturales de tres autores diaspóricos", 1616: Anuario de Literatura Comparada, 2, pp. 257-268.

AmBrosinI, Maurizio (2008). Un'altra globalizzazione. La sfida delle relazioni transnazionali. Bologna: II Mulino.

ANGELINI, Federica (2013). II pensiero nomade: scrittrici migranti raccontano l'Italia multietnica. Tesis doctoral dirigida por César Domínguez. Santiago: Universidade de Santiago de Compostela.

AnZALdúA, Gloria (1987). Borderlands/La Frontera. The New Mestiza. San Francisco: Aunt Lute Books.

ARnau I SegarRA, Pilar (2016). "L'hybridité identitaire dans une littérature émergente: l'écriture du «moi» hybride dans l'œuvre autobiographique des écrivains catalans d'origine maghrébine", Babel, 33, $<$ http://babel.revues.org/4540>.

BeRLAGE, Pauline (2013). "La paradoja de la literatura de la migración latinoamericana: algunas reflexiones a partir de la obra de Juan Carlos Méndez Guédez". En Giuliani, Luigi, Leonarda Trapassi y Javier Martos (eds.), Far away is here. Lejos es aquí. Writing and migrations. Berlin: Frank \& Timme, pp. 39-58.

BERNECHEA NAVARRO, Sara (2013). "Usos y desuso de la noción de inmigrante en la literatura de la inmigración a través de los premios literarios". En Giuliani, Luigi, Leonarda Trapassi y Javier Martos (eds.), Far away is here. Lejos es aquí. Writing and migrations. Berlin: Frank \& Timme, pp. 23-37.

BESALÚ, Xavier (2009). "Estrangers, bàrbars, estranys... Els altres i nosaltres a Catalunya", Temps d'Educació, 36, p. 281-296, <http://www.raco.cat/index.php/TempsEducacio/article/view/139995>.

BorgnA, Eugenio (2001). L'arcipelago delle emozioni. Milano: Feltrinelli.

BRAIDOTTI, Rosi (1994). Nomadic subjects. Embodiment and sexual difference in contemporary feminist theory. New York; Chichester, West Sussex: Columbia University Press. [ed. cast. Sujetos nómadas. Barcelona: Paidós, 2000].

Bueno Alonso, Josefina (2010). "Del Magrib a Catalunya: veus de dones en català". En Climent, Laia (ed.). Desvelant secrets. Les dones de l'islam entre la tradició i la transgressió. València: Tres i Quatre, pp. 167-181.

CANDEL, Francesc [1964] (2008). Els altres catalans. Barcelona: Edicions 62. Prólogo de Najat El Hachmi.

CAMPOY-CuBillo, Adolfo (2013). "Representation and its Discontents: Maghrebian Voices and Iberian Diversity", Transmodernity: Journal of Peripheral Cultural Production of the Luso-Hispanic World, 3 (1), pp. 141158.

CAStEllano I SANZ, Margarida (2011). "Cartografies de la identitat catalana: les noves fesomies a la literatura catalana del s. XXI". En Actes del Simposi Internacional La Literatura que acull: infància, immigració i lectura. Barcelona: UAB-Gretel.

Celaya-Carrillo, Beatriz (2011). "Pánicos racistas: reflexiones sobre la 
inmigración en Cataluña y España a partir de un texto de Najat El Hachmi”, Modern Language Notes, 126.

ChAFFEE, Jessie (2016). "An Interview with Najat El Hachmi", Words without borders. The Online Magazine for International Literature, 30 mar, <http://www.wordswithoutborders.org/dispatches/article/an-interviewwith-najat-el-hachmi>.

Chiellino, Carmine (2013). "En busca del punto cero para convertirse en escritor intercultural”. En Giuliani, Luigi, Leonarda Trapassi y Javier Martos (eds.), Far away is here. Lejos es aquí. Writing and migrations. Berlin: Frank \& Timme, pp. 91-99.

CRAMERI, Kathryn (2014). "Hybridity and Catalonia's Linguistic Border: the Case of Najat El Hachmi”. En Flocel Sabaté (ed.), Hybrid Identities. Bern: Peter Lang, pp. 271-296.

El HACHMI, Najat (2004). Jo també sóc catalana. Barcelona: Edicions 62. (2008). L'últim patriarca. Barcelona: Edicions 62.

(2015a). La filla estrangera. Barcelona: Edicions 62.

(2015b). La hija extranjera. Traducción de Rosa Maria Prats. Barcelona: Destino.

EVANGELISTA, Elin-Maria (2013). "Writing in translation: A new self in a second language". En Anthony Cordingley (ed.), Self-Translation: Brokering Originality in Hybrid Culture. London-New Delhi-New York-Sydeny: Bloomsbury.

GARCÍA CANCLINI, Néstor (2004). Culturas híbridas. Estrategias para entrar y salir de la modernidad. México, D.F. / Buenos Aires: Sudamericana.

GERNALZICK, Nadja (2013). "Translinguality and Transculturality". En Alfonso de Toro (ed.), Translatio. Transmédialité et transculturalité en littérature, peinture, photographie et au cinéma. Amériques, Europe, Maghreb. Paris: L'Harmattan, pp. 81-95.

Glick Schiller, Nina, BASCH, Linda, Blanc-Szanton, Cristina (1992). "Transnationalism: A New Analytic Framework For Understanding Migration", Annals of the New York Academy of Sciences 645, pp. 1-24.

GNISCI, Armando (2010). "Escrituras migrantes”, Extravío. Revista electrónica de $\begin{array}{lllll}\text { literatura comparada, } \quad \mathrm{n} . \stackrel{0}{ } & 5, & \mathrm{pp} . & 1-7 \text {. }\end{array}$ <https://ojs.uv.es/index.php/extravio/article/view/2262/1861>.

GuIA, Aitana (2010).“De lenguas y horizontes. Europa vista por sus escritores inmigrantes de cultura islámica", Extravío. Revista electrónica de literatura comparada, $\mathrm{n} . \stackrel{0}{5}$, <https://ojs.uv.es/index.php/extravio/issue/view/158>.

HeINEMANN, Ute (1996). Novel-la entre dues llengües. El dilema català o castellà. Kassel: Reichenberger.

KING, Stewart (ed.) (2005). La cultura catalana de expression castellana. Estudios de literatura, teatro y cine. Kassel: Reichenberger.

KLEINER-LIEBAU, Désirée (2009). Migration and the Construction of National Identity in Spain. Madrid-Frankfurt am Main: Iberoamericana-Vervuert.

MANCINI, Tiziana (2006). Psicologia dell'identità etnica. Sé e appartenenze culturali. Roma: Carocci.

MARÍ MAYANS, Isidor (2015). "La situación sociolingüística del catalán: la evolución reciente", Confluenze, Vol. 7, n.ำ 2, pp. 46-60, 
<https://confluenze.unibo.it/article/view/5938/5658>.

MuÑoz CARROBles, Diego (2015). "Najat El Hachmi, marroquí y catalana", Quimera. Revista de literatura, noviembre, pp. 40-43.

NICHOLS, Geraldine (1989). Escribir, espacio proprio: Laforet, Matute, Moix, Tusquets, Riera y Roig por sí mismas. Minneapolis: Minn, Institute for the Study of Ideologies and Literature.

NiÑo-Murcia, Mercedes y Jason Rothman (2008). Bilingualism and identity. Spanish at the crossroads with other languages. Amsterdam/Philadelphia: John Benjamins Publishing Company.

PÉREZ-FIRMAT, Gustavo (1994). Life on the Hyfen: The Cuban-American way. Austin: University of Texas Press.

PÉREZ-SÁncheZ, Gema (2014). Prólogo. ¡Hay moros en la costa! Literatura marroquí fronteriza en castellano y catalán, Cristián H. Ricci. Madrid Frakfurt am Mein: Iberoamericana - Vervuert, pp. 13-15.

REAL, Neus (2009). "L'hora violeta, de Montserrat Roig", en Panorama crític de la literatura catalana, vol. VI, Segle XX. De la postguerra a l'actualitat, Enric Bou (dir.), pp. 621-622.

Rıccl, Cristián H. (2010a). "African voices in Contemporary Spain”. EnLuisMartínEstudillo, y Nicholas Spadaccini, (eds.), New Spain, New Literatures. Nashville, Tennessee: Vanderbilt University Press, pp. 203-231.

----- (2010b). "L'últim patriarca de Najat El Hachmi y el forjamiento de una identidad Amazigh-catalana", Journal of Spanish Cultural Studies, 11, 1, (2010), pp. 71-91.

----- (2010c). Literatura periférica en castellano y catalán: el caso marroquí. Madrid: Ediciones Clásicas, Ediciones del Orto.

----- (2014). ¡Hay moros en la costa! Literatura marroquí fronteriza en castellano y catalán. Madrid - Frakfurt am Mein: Iberoamericana - Vervuert.

RoIG I FRANSITORRA, Montserrat (1991). Digues que m'estimes encara que sigui mentida. Barcelona: Edicions 62.

RuEdA, Ana (2010). El retorno/el reencuentro. La inmigración en la literatura hispano-marroquí. Madrid - Frakfurt am Mein: Iberoamericana - Vervuert.

SALIH, Ruba (2008). "Identità, modelli di consumo e costruzione di sé tra il Marocco e l'Italia", en Riccio, Bruno (ed.) Migrazioni transnazionali dall'Africa. Etnografie multilocali a confronto. Torino: UTET, pp. 92-111.

SoNG, Rosi H. (2014). "Narrating identity in Najat El Hachmi's L'últim patriarca". En LuciaAiello, Joy Charnley y Mariangela Palladino (eds.), Displaced women. Multilingual Narratives of Migration in Europe. Newcastle upon Tyne: Cambridge Scholars Publishing, pp. 45-58.

SOTORRA, Andreu (2006). Entrevista con Najat El Hachmi. "L'origen no pot ser una àncora que ens condemni a estar sempre en el passat", Estris, vol. 147, enero-febrero 2006, pp. 15-18, $<$ http://www.andreusotorra.com/cornabou/docus/entrevistes/najatelhach mi.pdf>

VAliENTE, Oscar y Xavier Rambla (2009). "The new Other Catalans at school: decreasing unevenness but increasing isolation", Versión revisada de ID., 2009, "The new Other Catalans at school: decreasing unevenness but increasing isolation", International Studies in Sociology of Education, 19: 2, pp. 105-117. 
VELASCO, Juan Carlos (2009). "Transnacionalismo migratorio y ciudadanía en mutación”, Claves de razón práctica, n. 197 (nov. de 2009), pp. 32-41.

VIDAL ClaRAmONTE, M. ${ }^{a}$ Carmen África (2005). En los límites de la traducción. Granada: Comares.

- (2012). "Jo també sóc catalana: Najat El Hachmi, una vida traducida”, Quaderns. Revista de Traducció 19, pp. 237-250.

$\begin{array}{ccc}\text { (2015). "Traducir al atravesado", } & \text { Papers, } & \text { 100/3, } \\ \text { http://dx.doi.org/10.5565/rev/papers.2143. }\end{array}$

Fecha de recepción: 30 de abril de 2017

Fecha de aceptación: 11 de septiembre de 2017 